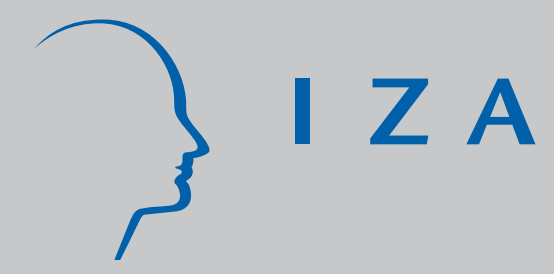

IZA DP No. 3649

The Portability of Human Capital and Immigrant Assimilation: Evidence for Spain

Esteve Sanromá

Raúl Ramos

Hipólito Simón

August 2008 


\title{
The Portability of Human Capital and Immigrant Assimilation: Evidence for Spain
}

\author{
Esteve Sanromá \\ IEB, Universitat de Barcelona \\ Raúl Ramos \\ AQR-IREA, Universitat de Barcelona \\ and IZA \\ Hipólito Simón \\ IEI, Universidad de Alicante
}

Discussion Paper No. 3649
August 2008

IZA

P.O. Box 7240

53072 Bonn

Germany

Phone: +49-228-3894-0

Fax: +49-228-3894-180

E-mail: iza@iza.org

\begin{abstract}
Any opinions expressed here are those of the author(s) and not those of IZA. Research published in this series may include views on policy, but the institute itself takes no institutional policy positions.

The Institute for the Study of Labor (IZA) in Bonn is a local and virtual international research center and a place of communication between science, politics and business. IZA is an independent nonprofit organization supported by Deutsche Post World Net. The center is associated with the University of Bonn and offers a stimulating research environment through its international network, workshops and conferences, data service, project support, research visits and doctoral program. IZA engages in (i) original and internationally competitive research in all fields of labor economics, (ii) development of policy concepts, and (iii) dissemination of research results and concepts to the interested public.
\end{abstract}

IZA Discussion Papers often represent preliminary work and are circulated to encourage discussion. Citation of such a paper should account for its provisional character. A revised version may be available directly from the author. 


\section{ABSTRACT}

\section{The Portability of Human Capital and Immigrant Assimilation: Evidence for Spain}

The existing literature on immigrant assimilation has highlighted the imperfect portability of human capital acquired by immigrants in their country of origin (Chiswick, 1978; Friedberg, 2000). This would explain the low levels of assimilation upon arrival in the new country, as well as the wide initial earnings gap. Recent studies (Chiswick and Miller, 2007 or Green, Kler and Leeves, 2007, among others) have dealt with this issue from the perspective of over-education. This study analyses the portability of immigrants' human capital into the Spanish job market according to their geographic origin. It also aims to compare the most notable empirical regularities found in the aforementioned studies with the situation in Spain. The results obtained indicate differing degrees of the transferability of human capital depending on geographic origin, as transferability is greater for countries that are highly developed or have a similar culture or language and lower for developing countries and those with more distant cultures. The evidence is relatively disparate for the two components of human capital as although it is particularly clear for schooling, it is less so for experience. The results also confirm that in Spain immigrants suffer from over-education, in both incidence and intensity, implying a higher relative wage penalty and a greater negative impact on immigrants from the second group of countries. As an immigrant's stay in Spain advances, a process of assimilation does exist, except for Asians and, in some circumstances, those from Sub-Saharan Africa, though the pace is very slow.

JEL Classification: J61, J31, J24

Keywords: immigration, over-education, wages, assimilation

Corresponding author:

Raúl Ramos

Grup d'Anàlisi Quantitativa Regional (AQR-IREA)

Department of Econometrics

University of Barcelona

Avenida Diagonal 690

08034 Barcelona

Spain

E-mail: rramos@ub.edu 


\section{THE PORTABILITY OF HUMAN CAPITAL AND IMMIGRANT ASSIMILATION. EVIDENCE FOR SPAIN ${ }^{1}$}

\section{Introduction and objectives}

Since its beginnings, the literature on immigrant assimilation has noted the limited portability of human capital acquired by immigrants in their country of origin. One basic reason for the low valuation of immigrant human capital lies in the insufficient command of the language in the country of arrival, which conditions the productivity of the rest of the immigrant's skills. Additionally, the education system in the country of origin may suffer from shortcomings that translate into a lower quality of education acquired in origin by immigrants. Furthermore, work experience in origin allows for human capital to be acquired that is specific to that country, i.e. adapted to a cultural, social, institutional, economic, technological or organisational environment that is often different from that of the destination country. As a result, the human capital imported by immigrants is comparatively less productive and, as such, less well paid than that of the native population, so that upon arrival in the new country a large difference in earnings is observed between the two groups. However, as the immigrant's stay in the country increases, the wage gap lessens - this is the phenomenon of assimilation - because the immigrant acquires knowledge and skills suited to the new job market.

The literature analysing these issues empirically is wide-ranging. Chiswick (1978) documented the lower marginal returns of immigrant human capital in the USA, noting as the reason the imperfect portability of human capital, and analysed assimilation for the first time. Borjas (1985, 1995a) confirmed these results while warning of the need to monitor the differing characteristics of immigrants from distinct cohorts. The results obtained for other economies with a tradition of immigration confirm the lower remuneration of immigrant human capital and the existence of the assimilation process, though at a different pace for each country (Chiswick and Miller, 1995, for Australia;

\footnotetext{
${ }^{1}$ Esteve Sanromá, Raúl Ramos and Hipólito Simón would like to express their gratitude for the support received from Spain's Ministerio de Educación y Ciencia (Plan Nacional de Investigación, Desarrollo e Innovación Científica) and Ministerio de Fomento through the programmes SEJ2007-65086, SEJ200504348/ECON and T75/2006, respectively. The authors are also grateful for the comments and contributions of Juan Sanchís and Mercedes Ayuso. The usual disclaimer applies.
} 
Baker and Benjamin, 1994, for Canada; Bell, 1997, for the UK; Schmidt, 1992, and Constant and Massey, 2003, for Germany, and Longva and Raaum, 2003, for Norway). An important step forward in this line of work was to separate studies undertaken by immigrants in their country and those conducted in the destination country. Thus, Shields and Wheatley Price (1998) estimate that non-white immigrants earn less for studies undertaken in origin compared with studies carried out in the UK. In analysing immigration to Israel, Friedberg (2000) also finds that human capital imported from culturally distant countries receives a lower remuneration than that acquired in the destination country, but is revaluated when complemented with studies carried out in Israel.

Two additional findings from this literature deserve mentioning. On the one hand, the portability of human capital acquired in origin is different depending on the type of country the immigrant comes from. Thus, the greater the distance in terms of language and culture, and the greater the difference in the degree of economic development, the less portable human capital acquired abroad becomes and the greater the initial inequality on the job market in comparison with native population (Shields and Wheatley Price, 1998 and Friedberg, 2000). On the other hand, the lesser the portability and the greater the initial gap, the greater the speed of assimilation, as the incentives to invest in human capital in the arrival country are stronger (Duleep and Regets, 1997).

Recent studies have dealt with this issue from the perspective of over-education. The underlying idea behind this new literature is the fact that the imperfect portability of human capital acquired in origin forces immigrants to accept jobs requiring a lower qualification than that which they acquired in their country, making them formally overeducated workers ${ }^{2}$. The main results of these recent studies can be synthesised into three empirical regularities. Firstly, there is a greater incidence of over-education among immigrants than among the native population. Secondly, the wage penalty associated with over-education is also greater for immigrants. And thirdly, immigrant workers succeed in reducing the difference in over-education with regard to the native population as their stay in the new country increases, i.e. the phenomenon of

\footnotetext{
${ }^{2}$ The possible differences in the qualities of the different national education systems limit the comparison of the native population and immigrants. Nevertheless, many other factors (such as an incomplete command of the language, qualifications not being recognised and studies adapted to another system of production) reduce the expected productivity of hiring immigrants, leading them to accept lower-paid jobs.
} 
assimilation takes place in over-education, as already occurred with earnings assimilation.

In addition to these common results, certain contributions from these studies deserve extra mention. Chiswick and Miller (2007) find that the greater the work experience in the country of origin, the greater the probability of over-education in the United States, which indicates low transferability not just of schooling but also of work experience acquired in origin. Their study is also one of the few in which over-education affects immigrants slightly less than it does the native population. However, important differences appear depending on the country of origin. In another study, Chiswick and Miller (2008) quantify that the educational mismatch explains almost two thirds of the different human capital returns among the native population and immigrants. In the case of Australia, Green, Kler and Leeves (2007) conclude not only that recent immigrants have a greater rate of over-education than the native-born population, the incidence is also higher among those from non-English-speaking countries, who also show lower returns for over-education. Kler (2006) confirms these same results for immigrants with tertiary studies. Using data from the United Kingdom, Lindley and Lenton (2006) obtain a greater percentage of over-education not just among immigrants but also for non-white members of the native-born population. In the case of Denmark, Nielsen (2007) is able to separate studies conducted in origin from those carried out in Denmark, as well as determining immigrants effective work experience once they are living in Denmark, along with the number of years of their stay. With this detailed information, Nielsen obtains some interesting results. On the one hand, over-education affects immigrants with studies from abroad more than natives and immigrants who have studied in Denmark, which clearly reveals that the core of the problem lies in the partial portability of human capital acquired in origin. On the other hand, immigrants with studies acquired in their own country reduce their over-education, i.e. they assimilate as they increase their effective work experience in Denmark, and (though to a lesser degree) as their stay in the country increases without necessarily holding down a job. Immigrants who have only studied in Denmark, meanwhile, improve their work match through effective work experience. As for the returns of years of over-education, this is lowest for immigrants with studies from abroad, followed by immigrants with Danish qualifications, and is highest for the native-born population. Finally, the OECD (2006) finds that in the 21 member countries studied, the percentage of over-educated 
workers is higher for immigrants than for the native-born population, albeit with notable differences among them, such as Greece and Spain (30\% and 19\% greater overeducation among immigrants, respectively), whereas in the United States and Switzerland the difference is only an additional 2.5\%. With data from 25 countries, the OECD (2007) obtains similar results when separating for men and women, except in the case of Slovakia (women), Switzerland (men) and New Zealand (both genderes), where over-education affects the native population more.

Within the framework of this literature, this study analyses the portability of immigrant human capital onto the Spanish job market according to geographic origin. It also aims to compare the most notable empirical regularities found in the aforementioned studies with the situation in Spain, by analysing over-education not just in terms of its incidence, but also by extending the study to the differentials in its intensity.

Studying the case of Spain is particularly interesting, firstly because it is a country with abundant, recent immigration. In little more than a decade Spain has become a country with migratory flows that make it stand out in an international context (OECD, 2007). It is the second, behind the United States, of the 33 OECD countries in the absolute number of immigrants per year, and the third, behind Luxembourg (2.65\%) and Switzerland (1.3\%), in the rate of immigration (1.23\%). This has meant a shift from 361,000 foreigners residing in Spain in 1991 ( $0.9 \%$ of the total population) to 4,482,568 on 1 January 2007 (9.94\% of the population). Furthermore, their unequal distribution throughout the country translates into an even greater weight of immigration in seven of the country's autonomous regions. These include the Balearic Isles (18.4\% of its population), the Region of Valencia (14.9\%), Murcia (14.4\%), Madrid (14.1\%) and Catalonia (13.4\%). These percentages already place Spain, and especially these regions, on levels comparable with, and even higher than, some European countries with a greater tradition of immigration.

Secondly, and unlike other countries, immigration to Spain comes from a highly varied range of countries, with origins as diverse as Latin America, the Maghreb and Eastern Europe. Furthermore, immigration from Latin America is characterised by sharing both language and culture with Spain but clearly having a lower level of development, as well as there being differences among the various countries on the continent. This 
feature is not common to other countries that have traditionally received immigration, such as the United States, the United Kingdom and Australia, in which immigrants with English as their mother tongue normally come from only a few countries, some of which have a similar level of development.

Thirdly and finally, the recent nature of the migratory phenomenon in Spain makes it impossible to consult similar databases to those used in other countries to analyse the phenomenon of immigrant assimilation. For this reason, the number of studies dealing with immigrant assimilation on the Spanish job market is very small (Amuedo-Dorantes and de la Rica, 2007; Fernández and Ortega, 2008; Sanromá, Ramos and Simón, 2005), and they have not been able to analyse wage assimilation (Simón, Sanromá and Ramos, 2008, analyse wage differences between the native population and immigrants in the whole of the distribution, using microdata from the 2002 Earnings Structure Survey, but are unable to analyse wage assimilation). The recent international literature mentioned previously opens up the possibility of analysing both the incomplete portability of human capital and immigrant assimilation from data relating to over-education, which is better suited to the available statistics on immigrants on the Spanish job market.

The contributions from this study are diverse. On the one hand, it analyses in detail the portability of immigrant human capital, an aspect still not dealt with for Spain and for which little international literature exists. On the other hand, it analyses immigrant assimilation in over-education, the same variable used recently for countries with a tradition of immigration, such as the United States, the United Kingdom, Australia and Denmark. Furthermore, it takes the novel approach of analysing the intensity of overeducation and not just its incidence, as has been the case in the literature up to now. It also analyses the returns of schooling years undertaken by immigrants, making a distinction between required study and surplus study, an aspect that has seen little analysis in the literature on the subject and which has never been considered for Spain before. Finally, the study analyses immigrants from both developed countries and developing economies, distinguishing, furthermore, among different regions of origin according to their language and their level of development. One particularly interesting feature is the opportunity to carry out initial separate analyses of the effect of language and of the level of development, due to the possibility of splitting Latin American into two areas according to the level of income. 
After this introduction, the second section presents the database. The third section describes the incidence and intensity of over-education of the native population and of immigrants from different areas of origin. The fourth section deals with the returns of schooling years of both the native population and those transferred by immigrants, with a breakdown according to their different origins. The fifth section studies the portability of human capital and its assimilation, with discrete choice models and regression models. The article ends with a final section presenting the main conclusions.

\section{Databases and sample characteristics}

Both the Population Census and the Labour Force Survey (LFS) offer individualised information on schooling and employment levels of Spaniards and foreigners, so the over-education of both groups can be calculated. Similarly, both statistical sources provide information on the immigrants' year of arrival, making it possible to study the portability of human capital and the possible immigrant assimilation over the course of time. The main difference between the two sources is the sample size, as the Census microdata contain a considerably higher number of immigrants than the LFS. The use of Census allows for differentiation by various areas of origin, a central aspect to study the differences in human capital portability according to geographic and cultural origin. For this reason, this study used the anonymous microdata sample file of the Population Census of 2001, produced by Spain's National Institute of Statistics (INE) and representing a five per cent of the total population. From this information it is possible to identify the nationality of individuals (a criterion used to identify them as immigrants), as well as the year of their arrival in Spain ${ }^{3}$. The study has worked with observations corresponding to economically active individuals between 16 and 65 years of age; immigrants with a minimum age of 16 years upon arrival in Spain were chosen as a way of ensuring that they had undertaken studies in their country of origin.

An additional difficulty in analysing the situation in Spain is that the recent nature of the immigration flows means it is not possible to obtain various cross-sections that

\footnotetext{
${ }^{3}$ In the context of this study, a limitation of the Census is the lack of information relating to immigrants' command of Spanish, making it impossible to analyse in detail its influence on the portability of human capital and its subsequent assimilation. The analysis details immigrants' regions of origin to indicate their knowledge of the Spanish language.
} 
essentially allow the changing make-up of immigrants and their characteristics to be monitored. This difficulty has been solved by taking as a sample only immigrants arriving in Spain after 1995, which brings several advantages. Firstly, this is a sevenyear cohort, which is even lower than the ten-yearly cross-section normally available when working with several censuses. Furthermore, this is a relatively homogenous group of immigrants within each geographic area of origin. And finally, it covers a single phase of economic expansion, characterised by intense job creation.

The information on nationality makes it possible to identify up to seven regions of immigrant origin - regions which are geographic but also cultural and economic. Specifically, for the purposes of this study they are described as the developed economies, the Southern Cone of South America (Argentina, Chile and Uruguay), the rest of Latin America (with a majority of immigrants from Ecuador and Colombia), countries in Eastern Europe (with a predominance of Romanians and Bulgarians), the Maghreb (Morocco, Algeria and Tunisia), the rest of Africa (mainly Senegalese and Nigerians), and Asia and the rest of the world, with a high number of Chinese and Pakistani immigrants ${ }^{4}$.

To calculate the differences in returns to schooling and over-education for Spaniards and immigrants, microdata was used from the 2002 Earnings Structure Survey (ESS). This survey includes wage earners working in establishments in the private sector with ten or more employees, with the exception of certain branches of activity, including the primary sector and domestic service. It records worker nationality, which is used to identify immigrants, though it does not provide the year of arrival in Spain, which has made it impossible to select those who have arrived most recently. The ESS provides ample information on workers (including wage, gender, age, studies, job, seniority, type of contract and working hours), making it particularly useful to estimate wage equations. This study analyses all the ESS sample observations for individuals between

\footnotetext{
${ }^{4}$ Developed economies are the EU-15 plus Norway, Switzerland, Iceland, Cyprus, Malta, the small European principalities, USA, Canada, Israel, Japan, Australia and New Zealand. The majority in this group are from the UK, Germany and Italy. The Rest of America is defined as countries on the American continent south of the USA, except for Argentina, Chile and Uruguay, a region here called the Southern Cone. Also included in Latin America is Equatorial Guinea, the only country in Africa where Spanish is the official language. Despite the fact that a large part of the Eastern European countries currently form part of the European Union, it was decided to make this distinction due to the notable differences in terms of development, especially Romania and Bulgaria, the countries with the greatest number of immigrants.
} 
16 and 65 years of age, and wage equations were estimated ${ }^{5}$ separately for Spaniards and immigrants, both as a whole and for various regions of origin ${ }^{6}$.

However, the ESS does have two limitations that can affect the results: on the one hand, the exclusion of primary and domestic service activities; and on the other, the exclusion of establishments with fewer than ten employees. In so much as immigrants have a greater presence in these areas, the fact that they are not included means they are slightly under-represented in the sample. Despite this, comparison of the ESS with various databases containing information relating to immigrants leads to the conclusion that the bias in immigrants' average wage is small (Simón, Ramos and Sanromá, 2007). However, the data on over-education obtained with this source may reflect a lower incidence and intensity, as it excludes sectors with high over-education (especially for immigrants) such as the primary sector and domestic service, yet the survey does include immigrants who arrived a long time previously that have been able to assimilate by reducing their over-education on the Spanish job market.

\section{Over-education: incidence and intensity}

The literature has developed three procedures to measure educational mismatch: the objective method, the subjective method and the statistical method (mean or mode) ${ }^{7}$. Usually, the choice of one method or another tends to be determined by the availability of statistical information rather than for theoretical reasons. In this case, the information available in both the Earnings Structure Survey and the Population Census has made it possible to calculate statistical measures (mean and mode) of the educational mismatch.

\footnotetext{
${ }^{5}$ The wage concept used is the gross wage-per-hour logarithm, calculated as the annual wage divided by the number of hours worked during the year. This covers commissions, meal allowances, bonuses and any other payments, with the exception of overtime.

${ }^{6}$ From the geographic origins set out in the survey, five regions were put together in a way that most closely resembles those mentioned previously. These are: 1) EU-15 plus North America, which is very similar to the group here called "developed economies"; 2) Rest of Europe, with very few differences with regard to "Eastern Europe"; 3) Rest of America, which coincides with "Southern Cone" plus "Rest of Latin America"; 4) Africa, which groups together "Maghreb" and "Rest of Africa", and 5) Asia, which makes up the most part of "Asia and rest of the world".

${ }^{7}$ The objective method involves comparing workers' level of education with the levels needed to carry out the functions associated with their work position, according to a panel of experts. The subjective method is based on surveys in which individuals self-classify themselves directly into one of the aforementioned categories, or surveys enquiring about the nature of their job, which allows them to be classified indirectly. The statistical method considers workers who have a number of years of study above or below the average number of years of their job plus or minus a standard deviation, or alternatively below the mode (or the corrected mode). Sanromá, Ramos and Simón (2005) provide more details with regard to these procedures.
} 
Given that the statistical method tends to underestimate the educational mismatch, particularly in its version based on the mean (Groot and Maassen van den Brink, 2000), the reading of the results has focused, wherever possible, on the mode. For the purposes of comparison, the educational mismatch was also calculated for Spaniards and immigrants from the enlarged sample for Spain corresponding to the year 2000 from the European Community Household Panel (ECHP) ${ }^{8}$. Despite the smaller immigrant sample size in this database, it was used because it allows a subjective measure of the mismatch to be calculated.

Table 1 shows the results relating to the educational mismatch calculated with the Census microdata (statistical method), from the Earnings Structure Survey (statistical method) and from the ECHP (subjective and statistical methods). In line with the aforementioned international evidence, the incidence of educational mismatch is greater among immigrants: the percentage of individuals suitably educated is higher for Spaniards in all databases and with all criteria, except for the mean in the ESS. According to this survey, furthermore, the presence of over-education among immigrants is somewhat lower (around 2.5 percentage points) than among the native population. According to the ECHP, however, both statistical criteria reveal an overeducation of ten percentage points higher among immigrants, although by applying the subjective criteria the difference disappears ${ }^{9}$. Applying both statistical criteria to the Census microdata confirms that immigrants register a lower education match and a higher over-education match - between seven (mode) and ten (mean) percentage points. It should be remembered that for Spain the OECD (2006) obtains a higher incidence among immigrants, at 19 percentage points.

The difference in over-education results observed between the ESS and the other two databases (Census and ECHP) can be explained, at least in part, by the different nature of the ESS. As it is a survey for companies with more than ten workers, it is difficult for it to include immigrant wage-earners that do not have a work permit, who probably have less scope to reject jobs not suited to their level of education. Furthermore, as it

\footnotetext{
${ }^{8}$ The microdata used corresponds to the enlarged sample of data for Spain from the ECHP of the seventh cycle, year 2000.

${ }^{9}$ It should be made clear that the subjective criterion can produce very different results to the other criteria, as they can depend on workers' perceptions regarding their job. In this sense, it is difficult to explain how only 18.2 per cent of Spaniards have a job that corresponds to their level of studies, whereas half work above their educational possibilities.
} 
provides no information on the year of arrival, all immigrants have had to be considered, so that for a large number enough time may have past for assimilation to have occurred, at least in terms of an education match ${ }^{10}$. For this reason, it is clearly preferable to use census microdata, which although they do not guarantee the presence of all immigrants, they do minimise those absences, at least in comparative terms.

By applying both statistical criteria (mode and mean) to these census data, it is possible to observe the incidence of educational mismatch and over-education according to immigrants' country of origin (table 2). The existence of big differences in the percentage of over-educated workers between the different origins stands out above all. Thus, whereas immigrants from developed countries and the Southern Cone record a lower incidence of over-education (21.5\% and $22.4 \%$, respectively), at the other extreme immigrants from the Maghreb (55.4\%) and the rest of Africa (48.1\%), followed by Asians (38.7\%), suffer a greater incidence of over-education. These simple calculations provide indications of an incomplete transferability of immigrants' human capital, particularly those from countries with a lower level of development and a culture that is distant from that of Western society.

However, immigrants not only suffer from a greater incidence of over-education, they also show a greater intensity, measured in the number of "surplus" years of study (table 3 , with data obtained by applying the mode criterion ${ }^{11}$ ). Indeed, the percentage of immigrants with intense over-education is clearly higher than that of the native population. Thus, ten per cent of immigrants have five or more years of surplus studies, a figure which drops to six per cent for the native-born population.

\footnotetext{
${ }^{10}$ A second important difference between the ESS and, for example, the Census, is each one's different sector coverage, as the 2002 ESS excluded agriculture, fishing, homes that employ domestic staff, public administration and extraterritorial bodies. In any case, the differences observed in table 1 do not respond to this unequal cover. By restricting census microdata to the sectors surveyed by the ESS, very similar over-education percentages are obtained.

${ }^{11}$ The results obtained from the mean criterion are similar and are available upon request from the authors.
} 
TABLE 1

Incidence of educational mismatch.

\begin{tabular}{|c|c|c|c|c|c|c|c|c|}
\hline & & \multicolumn{2}{|c|}{ ESS 2002} & \multicolumn{3}{|c|}{ ECHP 2000} & \multicolumn{2}{|c|}{ Census 2001* } \\
\hline & & Mode & Mean & Subjective & Mode & Mean & Mode & Mean \\
\hline \multirow{3}{*}{ 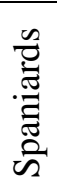 } & Properly educated & $48.19 \%$ & $75.94 \%$ & $18.22 \%$ & $39.04 \%$ & $69.68 \%$ & $42.63 \%$ & $71.54 \%$ \\
\hline & Under-educated & $28.36 \%$ & $9.57 \%$ & $49.94 \%$ & $31.22 \%$ & $15.75 \%$ & $29.21 \%$ & $12.99 \%$ \\
\hline & Over-educated & $23.46 \%$ & $14.48 \%$ & $31.84 \%$ & $29.74 \%$ & $14.37 \%$ & $28.16 \%$ & $15.46 \%$ \\
\hline \multirow{3}{*}{ 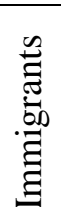 } & Properly educated & $44.42 \%$ & $77.06 \%$ & $13.15 \%$ & $34.26 \%$ & $60.96 \%$ & $33.24 \%$ & $57.91 \%$ \\
\hline & Under-educated & $34.67 \%$ & $11.23 \%$ & $56.57 \%$ & $26.29 \%$ & $14.34 \%$ & $31.30 \%$ & $16.23 \%$ \\
\hline & Over-educated & $20.91 \%$ & $11.71 \%$ & $30.28 \%$ & $39.44 \%$ & $24.70 \%$ & $35.46 \%$ & $25.86 \%$ \\
\hline
\end{tabular}

* Notes: In the case of all the Census 2001 data, the analysis was limited to immigrants arriving in Spain after 1994. The results obtained for the 37,899 observations included in the census sample, corresponding to all immigrants, are similar. 
TABLE 2

Incidence of educational mismatch. Detailed results.

\begin{tabular}{|c|c|c|c|}
\hline & Census 2001 & Mode & Mean \\
\hline \multirow{3}{*}{ 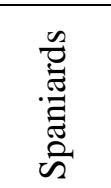 } & Properly educated & $42.6 \%$ & $71.5 \%$ \\
\hline & Under-educated & $29.2 \%$ & $13.0 \%$ \\
\hline & Over-educated & $28.2 \%$ & $15.5 \%$ \\
\hline \multirow{3}{*}{ 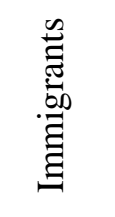 } & Properly educated & $33.2 \%$ & $57.9 \%$ \\
\hline & Under-educated & $31.3 \%$ & $16.2 \%$ \\
\hline & Over-educated & $35.5 \%$ & $25.9 \%$ \\
\hline \multirow{3}{*}{ 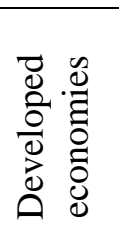 } & Properly educated & $37.3 \%$ & $58.3 \%$ \\
\hline & Under-educated & $41.2 \%$ & $31.3 \%$ \\
\hline & Over-educated & $21.5 \%$ & $10.4 \%$ \\
\hline \multirow{3}{*}{ 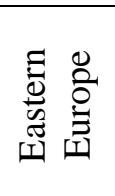 } & Properly educated & $32.8 \%$ & $60.0 \%$ \\
\hline & Under-educated & $41.7 \%$ & $29.1 \%$ \\
\hline & Over-educated & $25.5 \%$ & $10.9 \%$ \\
\hline \multirow{3}{*}{ 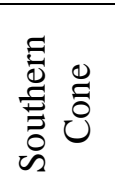 } & Properly educated & $35.6 \%$ & $57.9 \%$ \\
\hline & Under-educated & $42.0 \%$ & $32.4 \%$ \\
\hline & Over-educated & $22.4 \%$ & $9.7 \%$ \\
\hline \multirow{3}{*}{ 莺泀 } & Properly educated & $33.7 \%$ & $59.5 \%$ \\
\hline & Under-educated & $40.1 \%$ & $29.8 \%$ \\
\hline & Over-educated & $26.1 \%$ & $10.7 \%$ \\
\hline \multirow{3}{*}{ 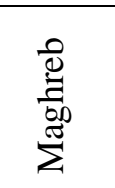 } & Properly educated & $28.8 \%$ & $51.6 \%$ \\
\hline & Under-educated & $15.8 \%$ & $10.2 \%$ \\
\hline & Over-educated & $55.4 \%$ & $38.2 \%$ \\
\hline \multirow{3}{*}{ 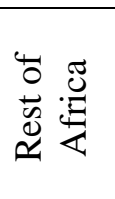 } & Properly educated & $30.8 \%$ & $57.0 \%$ \\
\hline & Under-educated & $21.1 \%$ & $12.7 \%$ \\
\hline & Over-educated & $48.1 \%$ & $30.3 \%$ \\
\hline \multirow{3}{*}{ 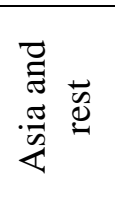 } & Properly educated & $34.5 \%$ & $57.0 \%$ \\
\hline & Under-educated & $26.8 \%$ & $20.8 \%$ \\
\hline & Over-educated & $38.7 \%$ & $22.2 \%$ \\
\hline
\end{tabular}

Notes: The analysis was carried out using 2001 Census data. 
TABLE 3

Intensity of educational mismatch by levels of studies.

\begin{tabular}{cccccc|c|cccccc}
\hline Spaniards & -5 or fewer & -4 & -3 & -2 & -1 & 0 & 1 & 2 & 3 & 4 & 5 or more \\
\hline Illiterate/no studies & $100 \%$ & $0 \%$ & $0 \%$ & $0 \%$ & $0 \%$ & $0 \%$ & $0 \%$ & $0 \%$ & $0 \%$ & $0 \%$ & $0 \%$ & $100 \%$ \\
\hline Primary & $2 \%$ & $0 \%$ & $86 \%$ & $0 \%$ & $0 \%$ & $12 \%$ & $0 \%$ & $0 \%$ & $0 \%$ & $0 \%$ & $0 \%$ \\
\hline Basic secondary & $1 \%$ & $7 \%$ & $1 \%$ & $0 \%$ & $0 \%$ & $85 \%$ & $0 \%$ & $0 \%$ & $6 \%$ & $0 \%$ & $0 \%$ \\
\hline Medium vocational diploma & $5 \%$ & $0 \%$ & $14 \%$ & $3 \%$ & $0 \%$ & $0 \%$ & $76 \%$ & $0 \%$ & $0 \%$ & $2 \%$ & $0 \%$ & $100 \%$ \\
\hline Higher secondary & $5 \%$ & $6 \%$ & $0 \%$ & $0 \%$ & $21 \%$ & $8 \%$ & $0 \%$ & $0 \%$ & $59 \%$ & $0 \%$ & $2 \%$ & $100 \%$ \\
\hline Higher vocational diploma & $7 \%$ & $0 \%$ & $3 \%$ & $0 \%$ & $0 \%$ & $23 \%$ & $3 \%$ & $0 \%$ & $0 \%$ & $62 \%$ & $2 \%$ & $100 \%$ \\
\hline Degree & $0 \%$ & $0 \%$ & $0 \%$ & $15 \%$ & $0 \%$ & $41 \%$ & $0 \%$ & $0 \%$ & $16 \%$ & $3 \%$ & $25 \%$ & $100 \%$ \\
\hline Master's/Doctorate & $0 \%$ & $0 \%$ & $0 \%$ & $0 \%$ & $0 \%$ & $62 \%$ & $0 \%$ & $8 \%$ & $0 \%$ & $0 \%$ & $30 \%$ & $100 \%$ \\
\hline TOTAL & $7 \%$ & $3 \%$ & $16 \%$ & $2 \%$ & $2 \%$ & $43 \%$ & $5 \%$ & $1 \%$ & $8 \%$ & $8 \%$ & $6 \%$ & $100 \%$ \\
\hline
\end{tabular}

\begin{tabular}{cccccc|c|cccccc}
\hline Immigrants & -5 or fewer & -4 & -3 & -2 & -1 & 0 & 1 & 2 & 3 & 4 & 5 or more \\
\hline Illiterate/no studies & $100 \%$ & $0 \%$ & $0 \%$ & $0 \%$ & $0 \%$ & $0 \%$ & $0 \%$ & $0 \%$ & $0 \%$ & $0 \%$ & $0 \%$ & $100 \%$ \\
\hline Primary & $1 \%$ & $0 \%$ & $78 \%$ & $0 \%$ & $0 \%$ & $21 \%$ & $0 \%$ & $0 \%$ & $0 \%$ & $0 \%$ & $0 \%$ & $100 \%$ \\
\hline Basic secondary & $1 \%$ & $3 \%$ & $1 \%$ & $0 \%$ & $0 \%$ & $84 \%$ & $0 \%$ & $0 \%$ & $11 \%$ & $0 \%$ & $0 \%$ & $100 \%$ \\
\hline Medium vocational diploma & $4 \%$ & $0 \%$ & $7 \%$ & $1 \%$ & $0 \%$ & $0 \%$ & $81 \%$ & $0 \%$ & $0 \%$ & $7 \%$ & $0 \%$ & $100 \%$ \\
\hline Higher secondary & $6 \%$ & $3 \%$ & $0 \%$ & $0 \%$ & $9 \%$ & $4 \%$ & $0 \%$ & $0 \%$ & $73 \%$ & $0 \%$ & $5 \%$ & $100 \%$ \\
\hline Higher vocational diploma & $3 \%$ & $0 \%$ & $1 \%$ & $0 \%$ & $0 \%$ & $5 \%$ & $1 \%$ & $0 \%$ & $0 \%$ & $83 \%$ & $7 \%$ & $100 \%$ \\
\hline Degree & $0 \%$ & $0 \%$ & $0 \%$ & $12 \%$ & $0 \%$ & $11 \%$ & $0 \%$ & $0 \%$ & $10 \%$ & $3 \%$ & $65 \%$ & $100 \%$ \\
\hline Master's/Doctorate & $0 \%$ & $0 \%$ & $0 \%$ & $0 \%$ & $0 \%$ & $38 \%$ & $0 \%$ & $5 \%$ & $0 \%$ & $0 \%$ & $57 \%$ & $100 \%$ \\
\hline TOTAL & $13 \%$ & $1 \%$ & $16 \%$ & $1 \%$ & $0 \%$ & $33 \%$ & $3 \%$ & $0 \%$ & $6 \%$ & $16 \%$ & $10 \%$ & $100 \%$ \\
\hline
\end{tabular}

\begin{tabular}{cccccc|c|cccccc}
\hline $\begin{array}{c}\text { Immigrants from developed } \\
\text { economies }\end{array}$ & -5 or fewer & -4 & -3 & -2 & -1 & 0 & 1 & 2 & 3 & 4 & $\begin{array}{c}5 \text { or } \\
\text { more }\end{array}$ \\
\hline Illiterate/no studies & $100 \%$ & $0 \%$ & $0 \%$ & $0 \%$ & $0 \%$ & $0 \%$ & $0 \%$ & $0 \%$ & $0 \%$ & $0 \%$ & $0 \%$ & $100 \%$ \\
\hline Primary & $4 \%$ & $0 \%$ & $91 \%$ & $0 \%$ & $0 \%$ & $5 \%$ & $0 \%$ & $0 \%$ & $0 \%$ & $0 \%$ & $0 \%$ & $100 \%$ \\
\hline Basic secondary & $4 \%$ & $8 \%$ & $1 \%$ & $0 \%$ & $0 \%$ & $83 \%$ & $0 \%$ & $0 \%$ & $3 \%$ & $0 \%$ & $0 \%$ & $100 \%$ \\
\hline Medium vocational diploma & $11 \%$ & $0 \%$ & $9 \%$ & $2 \%$ & $0 \%$ & $0 \%$ & $77 \%$ & $0 \%$ & $0 \%$ & $2 \%$ & $0 \%$ & $100 \%$ \\
\hline Higher secondary & $9 \%$ & $4 \%$ & $0 \%$ & $0 \%$ & $12 \%$ & $8 \%$ & $0 \%$ & $0 \%$ & $66 \%$ & $0 \%$ & $1 \%$ & $100 \%$ \\
\hline Higher vocational diploma & $10 \%$ & $0 \%$ & $1 \%$ & $0 \%$ & $0 \%$ & $13 \%$ & $2 \%$ & $0 \%$ & $0 \%$ & $73 \%$ & $2 \%$ & $100 \%$ \\
\hline Degree & $0 \%$ & $0 \%$ & $0 \%$ & $26 \%$ & $0 \%$ & $17 \%$ & $0 \%$ & $0 \%$ & $16 \%$ & $3 \%$ & $38 \%$ & $100 \%$ \\
\hline Master's/Doctorate & $0 \%$ & $0 \%$ & $0 \%$ & $0 \%$ & $0 \%$ & $54 \%$ & $0 \%$ & $8 \%$ & $0 \%$ & $0 \%$ & $38 \%$ & $100 \%$ \\
\hline TOTAL & $7 \%$ & $2 \%$ & $8 \%$ & $3 \%$ & $1 \%$ & $37 \%$ & $4 \%$ & $2 \%$ & $7 \%$ & $15 \%$ & $14 \%$ & $100 \%$ \\
\hline
\end{tabular}

\begin{tabular}{cccccc|c|c|ccccc}
\hline $\begin{array}{c}\text { Immigrants from developing } \\
\text { economies }\end{array}$ & -5 or fewer & -4 & -3 & -2 & -1 & 0 & 1 & 2 & 3 & 4 & $\begin{array}{c}5 \text { or } \\
\text { more }\end{array}$ \\
\hline Illiterate/no studies & $100 \%$ & $0 \%$ & $0 \%$ & $0 \%$ & $0 \%$ & $0 \%$ & $0 \%$ & $0 \%$ & $0 \%$ & $0 \%$ & $0 \%$ & $100 \%$ \\
\hline Primary & $1 \%$ & $0 \%$ & $77 \%$ & $0 \%$ & $0 \%$ & $22 \%$ & $0 \%$ & $0 \%$ & $0 \%$ & $0 \%$ & $0 \%$ & $100 \%$ \\
\hline Basic secondary & $1 \%$ & $2 \%$ & $1 \%$ & $0 \%$ & $0 \%$ & $84 \%$ & $0 \%$ & $0 \%$ & $12 \%$ & $0 \%$ & $0 \%$ & $100 \%$ \\
\hline Medium vocational diploma & $3 \%$ & $0 \%$ & $7 \%$ & $1 \%$ & $0 \%$ & $0 \%$ & $82 \%$ & $0 \%$ & $0 \%$ & $7 \%$ & $0 \%$ & $100 \%$ \\
\hline Higher secondary & $5 \%$ & $3 \%$ & $0 \%$ & $0 \%$ & $8 \%$ & $3 \%$ & $0 \%$ & $0 \%$ & $75 \%$ & $0 \%$ & $7 \%$ & $100 \%$ \\
\hline Higher vocational diploma & $2 \%$ & $0 \%$ & $1 \%$ & $0 \%$ & $0 \%$ & $4 \%$ & $1 \%$ & $0 \%$ & $0 \%$ & $84 \%$ & $8 \%$ & $100 \%$ \\
\hline Degree & $0 \%$ & $0 \%$ & $0 \%$ & $7 \%$ & $0 \%$ & $9 \%$ & $0 \%$ & $0 \%$ & $7 \%$ & $2 \%$ & $73 \%$ & $100 \%$ \\
\hline Master's/Doctorate & $0 \%$ & $0 \%$ & $0 \%$ & $0 \%$ & $0 \%$ & $30 \%$ & $0 \%$ & $4 \%$ & $0 \%$ & $0 \%$ & $66 \%$ & $100 \%$ \\
\hline TOTAL & $14 \%$ & $1 \%$ & $17 \%$ & $0 \%$ & $0 \%$ & $33 \%$ & $3 \%$ & $0 \%$ & $6 \%$ & $16 \%$ & $9 \%$ & $100 \%$ \\
\hline
\end{tabular}

Notes: The calculations were made using 2001 Census data and by applying the mode criterion. 
By calculating the intensity of over-education separately for immigrants from developed and developing countries, it can be proven that over-education is more intense for those from developing companies when comparing the same levels of education. Thus, postgraduate-qualified immigrants with at least five years of over-education make up $38 \%$ of those arriving from developed countries, but $66 \%$ of those coming from other countries (30\% for Spaniards). For graduates, the figures are $38 \%$ and $73 \%$, respectively (25\% for Spaniards). This not only confirms the previous results regarding the limited portability of human capital acquired through the education system in the country of origin, it also emphasises that the difficulty can be even greater for university qualifications, particularly when acquired in countries with a lower level of development. What may contribute to this is that some qualifications may not be recognised and employers may mistrust the quality of these degrees, particularly when there is an excess of supply of graduates from Spanish universities.

In short, the results obtained reveal that over-education punishes immigrants more in both incidence and intensity, very probably due to the incomplete portability of human capital, and that the problem is worse for immigrants from countries with lower levels of development and a more distant language and culture.

\section{Over-education and wages: returns of transferred studies}

The analysis of the returns to schooling for Spaniards and immigrants, and particularly the different remuneration of the years of over-education, requires an estimation of ORU-type (over-required under-education) wage equations. This is a semi-logarithmic Mincerian earnings function, in which the years of study are broken down into three components: over-education $\left(s^{o}\right)$, suitable education $\left(s^{r}\right)$, and under-education $\left(s^{u}\right)$ :

$$
\ln W_{i}=\gamma+\beta^{o} \cdot s_{i}^{o}+\beta^{r} \cdot s_{i}^{r}+\beta^{u} \cdot s_{i}^{u}+\alpha \cdot z_{i}+u_{i}
$$

where $\ln W_{i}$ is the natural logarithm of the hourly wage of individual $i$; $s_{i}$ are the years of study of individual $i$, but broken down into years of over-education $\left(s_{i}^{o}\right)$, years required 
$\left(s_{i}^{r}\right)$ and years of under-education $\left(s_{i}^{u}\right)$, and $z_{i}$ includes other individual variables affecting earnings, such as work experience, gender, working part-time or other aspects of the particular job. Finally, it is assumed that $u_{i}$ is a random disturbance term distributed as a normal variable with zero expectation and constant variance.

Table 4 shows the returns per year of study of required education, over-education and under-education, from both the ESS and the ECHP (for comparative purposes the mismatch is measured with both the mean and mode criteria ${ }^{12}$ ). In both samples estimations for the native population confirm the usual results in the abundant literature on the subject. On the one hand, the required number of years of study has the greatest returns. On the other hand, the years of over-education receive positive remuneration, though clearly lower than the required years. Finally, the years of under-education perceive negative payment. These same effects are observed in immigrants, but only in the ESS sample. The anomalous results obtained with the ECHP may be related to the smaller immigrant sample size on that database (only 251 individuals).

Comparing the returns for years of education between Spaniards and immigrants leads to various interesting results. Firstly, the marginal return of one year of suitable study is quite similar between the two groups, with a difference not reaching one percentage point. This result appears to indicate that, in line with Chiswick and Miller (2008), the differences in returns to schooling between natives and immigrants can be explained by the educational mismatch. Secondly, the remuneration of each year of over-education is, without exception, much higher for Spaniards than for immigrants. The implication is that the fact of being over-educated receives a higher wage penalty for immigrants than for the native population.

For a more in-depth analysis, the same ORU-type wage equations were estimated for immigrants from different areas of origin. Focusing on the results obtained with the data generated by the mode criterion ${ }^{13}$, one year of necessary studies for a job has different marginal returns depending on the country of origin. On the one hand, immigrants from the EU-15 and North America (as well as Asia, surprisingly) perceive returns at around

\footnotetext{
${ }^{12}$ Even though in the ECHP it is possible to identify the educational mismatch with the subjective criterion, from the interviewee's response it is not possible to quantify the number of years of "surplus" or "lacking" education, nor the returns per year of mismatch.

${ }^{13}$ Estimations carried out by applying the mean criterion produce similar results.
} 
$10 \%$, slightly higher than the $9 \%$ for Spaniards; on the other hand, immigrants from Latin America (6.5\%), non-EU Europe (5.6\%) and particularly Africa (3.1\%) obtain a clearly lower returns from their required studies. These results do not allow for a discussion on the difficulties of transferring generic human capital, but rather it can be attributed to the existence of discriminatory practices in companies' pay policies. Alternatively it could be explained by the existence of an intense segregation of immigrants from developing countries in companies with low salaries, where they would be over-represented (Simón, Sanromá and Ramos, 2008).

The returns of surplus years of study (over-education) - always lower than that of required studies - is as high for immigrants from the EU-15 and North America (4.4\%) as for Spaniards. The figure is lower for Latin Americans (1.7\%), and is non-existent for Eastern Europeans, Asians and Africans. Immigrants from backward economies and distant cultures, therefore, not only register over-education in a more generalised way and suffer it with greater intensity; they also receive no remuneration for the many years of surplus education. It can be stated with confidence that for these immigrants their levels of education have a minimum level of transferability onto the Spanish job market. 
TABLE 4

Wage returns per year of necessary study, under-education and over-education.

\begin{tabular}{ll|cc}
\hline ECHP 2000 & Spaniards & Immigrants \\
\hline \multirow{3}{*}{ Mode } & Required education & $0.077^{* * *}$ & $0.079^{* * *}$ \\
\cline { 2 - 4 } & Under-education & $-0.046^{* * *}$ & -0.008 \\
\cline { 2 - 4 } & Over-education & $0.029^{* * *}$ & -0.018 \\
\hline \multirow{2}{*}{ Mean } & Required education & $0.089^{* * *}$ & $0.098^{* * *}$ \\
\cline { 2 - 4 } & Under-education & $-0.040^{* * *}$ & -0.006 \\
\cline { 2 - 4 } & Over-education & $0.027^{* * *}$ & -0.001 \\
\hline
\end{tabular}

\begin{tabular}{cl|cc|}
\hline ESS 2002 & Spaniards & Immigrants \\
\hline \multirow{2}{*}{ Mode } & Required education & $0.090^{* * *}$ & $0.083^{* * *}$ \\
\cline { 2 - 4 } & Under-education & $-0.043^{* * *}$ & $-0.049^{* * *}$ \\
\cline { 2 - 4 } & Over-education & $0.044^{* * *}$ & $0.017^{* * *}$ \\
\hline \multirow{2}{*}{ Mean } & Required education & $0.101^{* * *}$ & $0.097^{* * *}$ \\
\cline { 2 - 4 } & Under-education & $-0.025^{* * *}$ & $-0.026^{* * *}$ \\
\cline { 2 - 4 } & Over-education & $0.042^{* * *}$ & $0.021^{* * *}$ \\
\hline
\end{tabular}

\begin{tabular}{cl|c|c|c|c|c}
\hline \multirow{2}{*}{ ESS 2002} & $\begin{array}{c}\text { EU-15 and } \\
\text { North America }\end{array}$ & $\begin{array}{c}\text { Rest } \\
\text { Europe }\end{array}$ & $\begin{array}{c}\text { Rest } \\
\text { America }\end{array}$ & Africa & Asia \\
\hline \multirow{2}{*}{ Mode } & Required education & $0.098^{* * *}$ & $0.056^{* * *}$ & $0.065^{* * *}$ & $0.031^{* * *}$ & $0.100^{* * *}$ \\
\cline { 2 - 6 } & Under-education & $-0.051^{* * *}$ & $-0.054^{* * *}$ & $-0.042^{* * *}$ & $-0.017^{* * *}$ & $-0.046^{* * *}$ \\
\cline { 2 - 6 } & Over-education & $0.044^{* * *}$ & -0.003 & $0.017^{* * *}$ & 0.001 & 0.018 \\
\hline \multirow{2}{*}{ Mean } & Required education & $0.105^{* * *}$ & $0.078^{* * *}$ & $0.081^{* * *}$ & $0.051^{* * *}$ & $0.118^{* * *}$ \\
\cline { 2 - 7 } & Under-education & $-0.025^{* * *}$ & $-0.054^{* * *}$ & $-0.022^{* * *}$ & -0.010 & -0.025 \\
\hline
\end{tabular}

Notes: The analysis was carried out by applying the mode criterion. Additional explicative variables included in the ORU equations for the hourly wage for individuals aged 16 to 65 years are gender, experience and its square, working parttime, and length of service and its square.

$*$, ** and *** indicate that the coefficient is statistically significant at $10 \%, 5 \%$ and $1 \%$, respectively. 


\section{Determinants of over-education. Portability of studies and assimilation}

Detailed analysis of the portability of immigrant human capital and assimilation was carried out initially based on an estimation of discrete choice models, and subsequently on linear regression models.

Thus, first of all an ordered logit model was estimated for an endogenous variable, with three categories ordered as follows: being unemployed, being over-educated and being suitably educated. Specifically, it was supposed that the probability of individual $i$ being unemployed, over-educated and properly educated would be explained by a series of factors relating to different individual characteristics (gender, studies and age ${ }^{14}$ ) and family characteristics (married and number of children), as well as the fact of being an immigrant for foreigners and the number of years spent in Spain. Territorial controls were also included (provincial dummy variables and variables relating to the size of the town of residence), as they were considered to affect both probability of finding a job and the type of match. From the estimation by maximum likelihood of the equations system formed by the ordered logit, it is possible to obtain estimations of the influence of each one of these factors on the probability of going from one of the three categories to the one immediately above.

It is important to point out that by considering the possibility that individuals may remain unemployed and not accept a job for which they are over-educated, this controls the possible endogeneity between work and over-education that may affect immigrants to a greater degree than it does Spaniards, as immigrants do not enjoy the family networks or social protection that could allow them to increase the time spent looking for a job that is suitable to their level of training. The proposed model is estimated jointly for Spaniards and immigrants, providing details in some specifications of the immigrants’ area of origin.

\footnotetext{
${ }^{14}$ The decision was made to include age rather than potential experience as the usual way to calculate this could lead to errors of measurement as a result of different institutional and social situations in each of the immigrants' countries of origin.
} 
The results of the different models (table 5) coincide in estimating a greater probability of males improving their position in the job market (going from unemployed to overeducated and suitably educated) than women. The number of years of study has a positive effect on the probability of improvement for women. Its relatively low effect must be related to the fact that, although having studies makes it easier to leave unemployment, the higher the level of education, the greater the probability of overeducation. Age, which in a way captures the effect of accumulating experience, is also positively related to job improvement. Regarding family variables, marriage and children mean a greater probability of improvement, which coincides with the wage increase normally associated with this status.

The results from model 1 indicate that upon arrival in Spain immigrants have a much lower probability of improving their place on the job market than do Spaniards of similar characteristics. This clearly indicates that the same number of years of study and the same approximate potential experience - but both acquired in the country of origin place immigrants at a clear disadvantage with regard to the native-born population, who have acquired their human capital in Spain. Human capital acquired abroad is therefore limited in its transferability to the Spanish job market. Finally, the number of years living in Spain, in which time immigrants can perfect their command of the language, establish contacts, accumulate learning, develop skills and acquire experience, all adapted to the Spanish job market, increases the probability of improving their situation on the job market, which can be interpreted as a clear sign of assimilation.

Model 2 replaces the "immigrant" dummy variable for seven variables reflecting the regions of origin, with the aim of investigating whether differences exist between areas. The results show that such differences do indeed exist. Upon arrival, the greatest probabilities of improvement, although always lower than those for a Spaniard, are recorded by immigrants from Asia and Africa, along with Latin Americans. Far from revealing degrees of portability of immigrant human capital, this result is very probably conditioned by the restrictions in liquidity of these immigrants upon arrival in Spain, and as a result by their lower wage reserve in comparison with other groups, which allows them to leave unemployment quickly, even though it may be through the black economy. 
Model 3 also allows for the pace of assimilation to differ depending on origin. It can be seen that each year living in Spain increases the probability of job improvement to the greatest extend for immigrants from Eastern Europe, the Maghreb and Western Europe, whereas assimilation is not observed for immigrants from Sub-Saharan Africa, Asia and the rest of the world, as the effect is not statistically significant at the usual levels. This result suggests the possibility that immigrants from these areas remain permanently trapped in lower-paid jobs, regardless of their levels of education.

In the analysis carried out so far, over-education has been a unique status, with no consideration of its seriousness or intensity. In other words, the probability of leaving unemployment or over-education has been studied by considering that the only possibility for improvement lies in a change of status. However, over-education can have differing degrees of intensity and, as such, reducing the intensity of over-education could be a form of job improvement, i.e. of becoming assimilated. The following analysis therefore deals with the intensity of over-education - the differences in the number of years of over-education.

With this objective, analysis of the portability of human capital and the process of assimilation was widened to consider the intensity of over-education. To go about this, two distinct modelling strategies were considered: firstly, the over-educated immigrants were separated into two groups - those with low and medium intensity (1 to 4 years of over-education) and those with high intensity (5 to 12 years) - and the determinants of belonging to one category or the other were analysed using discrete choice models; secondly, a linear regression model was estimated for the number of years of overeducation for each individual. 
TABLE 5

Determinants of the probability of being unemployed, over-educated or properly educated

\begin{tabular}{|c|c|c|c|}
\hline Odds-ratio & Model 1 & Model 2 & Model 3 \\
\hline Male & $1.44^{* * *}$ & $1.44 * * *$ & $1.44^{* * *}$ \\
\hline Years of study & $1.03^{* * *}$ & $1.03^{* * *}$ & $1.03^{* * *}$ \\
\hline Age & $1.01^{* * *}$ & $1.01^{* * *}$ & $1.01^{* * *}$ \\
\hline Married & $1.06^{* * *}$ & $1.06^{* * *}$ & $1.06^{* * *}$ \\
\hline Number of children & $1.13^{* * *}$ & $1.13^{* * *}$ & $1.13^{* * *}$ \\
\hline Immigrant & $0.53^{* * *}$ & & \\
\hline Developed economies & & $0.48^{* * *}$ & $0.46^{* * *}$ \\
\hline Eastern Europe & & $0.49 * * *$ & $0.46^{* * *}$ \\
\hline Southern Cone & & $0.45^{* * *}$ & $0.46^{* * *}$ \\
\hline Rest Latin America & & $0.56^{* * *}$ & $0.57 * * *$ \\
\hline Maghreb & & $0.47^{* * *}$ & $0.45^{* * *}$ \\
\hline Rest of Africa & & $0.51^{* * *}$ & $0.58 * *$ \\
\hline Asia and rest of world & & $0.62 * * *$ & $0.73 *$ \\
\hline Years of residence & $1.10^{* * *}$ & $1.10^{* * *}$ & \\
\hline x Developed economies & & & $1.12^{* * *}$ \\
\hline x Eastern Europe & & & $1.13^{* * *}$ \\
\hline x Southern Cone & & & $1.09 * *$ \\
\hline $\mathrm{x}$ Rest of Latin America & & & $1.09 * * *$ \\
\hline x Maghreb & & & $1.12^{* * *}$ \\
\hline $\mathrm{x}$ Rest of Africa & & & 1.06 \\
\hline $\mathrm{x}$ Asia and rest of world & & & 1.05 \\
\hline Pseudo R2 & 0.05 & 0.05 & 0.05 \\
\hline Observations & 691797 & 691797 & 691797 \\
\hline
\end{tabular}

Notes: The analysis was carried out using data from the 2001 Census, applying the mode criteria and based on the estimation of ordered logit models. All the models include set provincial effects and a control variable for residents of towns with more than 20,000 inhabitants.

$*$, ** and *** indicate that the coefficient is statistically significant at $10 \%, 5 \%$ and $1 \%$, respectively. 
Thus, the first approach to analysing the intensity of over-education consisted of estimating a binary logit model for the probability of being intensely over-educated with regard to having a low- or medium-intensity over-education. Again, the explicative variables include individual and family characteristics, the fact of being an immigrant and the number of years of residence, as well as the same regional controls. This approach is suitable taking into account the discrete nature of the variable analysed.

However, before proceeding to estimate this model, it is necessary to consider the fact that, for unemployed immigrants, it is impossible to determine what their educational mismatch is. Analysing the factors that determine the educational mismatch without considering that there is a group of individuals not in employment could lead to inaccurate results - the well-known problem of bias selection. To solve this issue, the model was estimated by applying a two-stage procedure as proposed by Heckman (1979). The first stage of the Heckman procedure would be to analyse the probability of having a job or not based on various individual characteristics, whereas the second stage would analyse the probability of being highly over-educated (5 or more years) as opposed to having a low or medium over-education (up to 4 years), including an additional explicative variable: the Heckman's lambda (obtained in the first stage as the inverse of the Mills ratio). This variable would include the effects of all uncontrolled characteristics relating to the fact that there are individuals not in employment. Introducing this variable into the binary logit also corrects possible problems in estimating the rest of the explicative variables resulting from the omission of relevant variables.

The model was estimated jointly for Spaniards and immigrants, making a distinction in some specifications for an immigrant's area of origin.

Although some of the models' results (table 6) are more closely related to the literature on over-education, they still merit a brief comment. Firstly, they confirm that academic studies increase the probability of intense over-education. This is a usual result in both international and Spanish literature, though normally it refers to the probability of being over-educated. Secondly, age seems to have a negative effect on the probability of being intensely over-educated. Although not a rigorous contrast, this result seems to confirm a 
certain substitutability between education and other forms of human capital, as proposed by the theory of human capital ${ }^{15}$.

Thirdly, men have a greater probability of intense over-education. This result differs from the more usual result found in the literature, which does not find that the gender variable has an effect on the probability of being over-educated (Groot and Maasen van den Brink, 2000). Finally, marriage has no effect on the probability of intense overeducation, whereas each child does produce a slight increase in this probability.

But the key variables in this analysis refer to the fact of being an immigrant, and the evidence (model 1) shows that upon arrival in Spain immigrants have a 13.3\% greater probability than the native population of being intensely over-educated (five or more years), which again points to the limited portability of their human capital. On the other hand, human capital acquired after their arrival has a positive effect as their period of stay increases, by reducing the probability of intense over-education, which can be considered a form of assimilation.

The specification of models 2 and 3 allow the situation to be distinguished by region of origin. As can be observed, the probability of intense over-education upon arrival is greater for immigrants from Eastern Europe, Sub-Saharan Africa, the Maghreb and Asia, whereas those with lower probabilities are from developed countries, followed by the Southern Cone and the rest of Latin America. It can be stated, then, that there are clear differences in the degree of transferability of human capital. Transferability is incomplete for immigrants from countries with lower levels of economic and technological development (Morocco, Senegal, Nigeria, China and Pakistan), a culture that is distant and a language (Arabic, Wolof, Yoruba, Mandarin and Urdu) that is neither Romance in origin and close to Spanish, nor Saxon in origin and close to English. On the other hand, human capital from developed countries and the Southern Cone seems to be highly adaptable to the Spanish job market and, as such, almost completely transferable. It is also interesting to note the difference between immigrants from the Southern Cone (basically Argentina) and the rest of Latin America (mainly

\footnotetext{
${ }^{15}$ More precise contrasts on the hypotheses of human capital can be found in, among others, Sicherman (1991) for the United States, Mendes de Oliveira, Santos and Kiker (2000) for Portugal, and García Serrano and Malo (1996) and Beneito, Ferri, Moltó and Uriel (1996) for Spain.
} 
Ecuador and Colombia), as both areas share language and culture, but differ in the level of economic and social development. Command of the Spanish language places both groups upon arrival at an advantage over other immigrants, but the economic and social differential give a more advantageous position to those from the Southern Cone.

In order to study the portability of human capital in greater detail, models 4 and 5 analyse whether the limitation affects studies undertaken or experience acquired, both in origin. For this two new variables were entered into the model, following a multiplicative specification. Specifically, the product between years of study and immigrant, and between age and immigrant, was entered. The results relating to these variables in model 4 show firstly that each year of study undertaken by immigrants in their country of origin increases the possibility of intense over-education with regard to Spaniards by $1.2 \%$, which clearly reveals the limited portability of studies undertaken abroad. Secondly, and on the contrary, the coefficient associated with the product between age and immigrant is not statistically significant at the usual levels, thus showing that experience acquired in origin is transferable to the Spanish job market. It can therefore be concluded that the limited portability of human capital can be explained to a large degree by the studies undertaken in origin.

As can be seen in model 5, studies undertaken in Sub-Saharan Africa are the least transferable to the Spanish job market, as each year of study there raises the probability of intense over-education by $8.3 \%$. They are followed by studies carried out in Latin America, Asia and the Maghreb. However, studies in developed countries are almost completely transferable, as the coefficient value is much lower and is not statistically significant at $5 \%$ (though it is at $10 \%$ ). 
TABLE 6

Determinants of the intensity of over-education (5 to 12 years of mismatch versus 1 to 4 years of mismatch)

\begin{tabular}{|c|c|c|c|c|c|}
\hline Marginal effects & Model 1 & Model 2 & Model 3 & Model 4 & Model 5 \\
\hline Male & $0.029 * * *$ & $0.029 * * *$ & $0.029 * * *$ & $0.029 * * *$ & $0.029 * * *$ \\
\hline Years of study & $0.059 * * *$ & $0.059 * * *$ & $0.059 * * *$ & $0.060 * * *$ & $0.059 * * *$ \\
\hline x Immigrant & & & & $0.012^{* * *}$ & \\
\hline x Developed economies & & & & & $0.006^{*}$ \\
\hline x Eastern Europe & & & & & $0.013^{* * *}$ \\
\hline x Southern Cone & & & & & $0.018 * *$ \\
\hline x Rest of Latin America & & & & & $0.021^{* * *}$ \\
\hline x Maghreb & & & & & $0.018^{* *}$ \\
\hline x Rest of Africa & & & & & $0.083^{* * *}$ \\
\hline $\mathrm{x}$ Asia and rest of world & & & & & $0.019 * *$ \\
\hline Age & $-0.001 * * *$ & $-0.001 * * *$ & $-0.001 * * *$ & $-0.001 * * *$ & $-0.001 * * *$ \\
\hline x Immigrant & & & & 0.0001 & \\
\hline x Developed economies & & & & & 0.0006 \\
\hline x Eastern Europe & & & & & 0.0003 \\
\hline x Southern Cone & & & & & 0.0004 \\
\hline x Rest of Latin America & & & & & 0.0002 \\
\hline x Maghreb & & & & & 0.0001 \\
\hline x Rest of Africa & & & & & 0.004 \\
\hline x Asia and rest of world & & & & & 0.001 \\
\hline Married & 0.000 & 0.000 & 0.000 & 0.000 & 0.000 \\
\hline Number of children & $0.002 * * *$ & $0.002 * * *$ & $0.002 * * *$ & $0.002 * * *$ & $0.002 * * *$ \\
\hline Immigrant & $0.133^{* * *}$ & & & $-0.047 * * *$ & \\
\hline Developed economies & & $0.036 * * *$ & $0.034^{* * *}$ & & $-0.048 * * *$ \\
\hline Eastern Europe & & $0.222 * * *$ & $0.259 * * *$ & & -0.038 \\
\hline Southern Cone & & $0.087 * * *$ & $0.085 * *$ & & $-0.062 * * *$ \\
\hline Rest of Latin America & & $0.125 * * *$ & $0.113^{* * *}$ & & $-0.066 * * *$ \\
\hline Maghreb & & $0.199 * * *$ & $0.285 * * *$ & & $-0.054 * *$ \\
\hline Rest of Africa & & $0.212^{* * *}$ & $0.177 * *$ & & $-0.066 * * *$ \\
\hline Asia and rest of world & & $0.154 * * *$ & $0.154 * *$ & & $-0.063 * * *$ \\
\hline Years of residence & $-0.076^{* * *}$ & $-0.006 * * *$ & & $-0.011 * * *$ & \\
\hline x Developed economies & & & $-0.006^{*}$ & & $-0.008 * *$ \\
\hline x Eastern Europe & & & $-0.014 * * *$ & & $-0.014 * * *$ \\
\hline x Southern Cone & & & -0.006 & & -0.010 \\
\hline x Rest of Latin America & & & $-0.004 * *$ & & -0.009 \\
\hline x Maghreb & & & $-0.012 * *$ & & $-0.014 * *$ \\
\hline x Rest of Africa & & & -0.003 & & $-0.010 * * *$ \\
\hline $\mathrm{x}$ Asia and rest of world & & & -0.006 & & -0.007 \\
\hline Lambda & 0.000 & 0.000 & 0.000 & 0.000 & 0.000 \\
\hline Pseudo $\mathrm{R}^{2}$ & 0.533 & 0.534 & 0.534 & 0.534 & 0.535 \\
\hline Observations & 225067 & 225067 & 225067 & 225067 & 225067 \\
\hline
\end{tabular}

Notes: The analysis was carried out using microdata from the 2001 Census by applying the mode criterion and by estimating binary logit models. All models include set provincial effects and a control variable for residents of towns with more than 20,000 inhabitants.

$*$, ** and $* * *$ indicate that the coefficient is statistically significant at $10 \%, 5 \%$ and $1 \%$, respectively. 
Having controlled for transferability of studies and experience, the remaining nonobservable characteristics for immigrants reduce the probability of intense overeducation by $4.7 \%$. The most plausible hypothesis to explain this result is migratory self-selection, by which immigrants have non-observable characteristics that help them to adapt to the Spanish job market.

Models 3 and 5 show additional results that are of interest with regard to assimilation. Not all immigrants show a process of assimilation that consists of reducing the probability of intense over-education as their time in Spain increases. For example, immigrants from Eastern Europe and the Maghreb have the quickest pace of assimilation, whereas the pace is considerably slower for Western immigrants. Asians do not assimilate on the Spanish job market ${ }^{16}$ despite having a high probability of being intensely over-educated upon arrival, due to the limited portability of their human capital. The results for other areas are less robust, as they are not statistically significant in one of the two models.

As mentioned previously, a second approach to analysing the intensity of overeducation was also taken. Specifically, and going into greater detail, a linear regression model was estimated for the number of years of over-education. This approach, based on the regression model, could prove unsuitable if the endogenous variable were to show a discrete nature, as would be the case by applying the mode criterion. For this reason, the number of years of over-education was measured by applying the mean criterion (but without the usual standard deviation margin), as the variable resulting from the comparison between an individual's level of education and the mean level of education by job type is continual. The exogenous variables include individual characteristics and family variables, the same regional controls and, where appropriate, the fact of being an immigrant and the number of years in Spain. Again, on this occasion the possible selection bias was solved by applying the same procedure in two stages, incorporating the Heckman's lambda as an additional regression factor. Estimations were

\footnotetext{
${ }^{16}$ The same result is recorded for immigrants from the Southern Cone, but it is worth bearing in mind that upon arrival they do not have a markedly different probability of over-education to that of Spaniards, which is not the case for Sub-Saharans and Asians.
} 
also made jointly for Spaniards and immigrants, detailing in some specifications the various regions of origin.

Table 7 shows the results obtained by estimating the regression model described in the earlier paragraphs. Results from the individual variables coincide with those obtained in the previous model of discrete choice. Thus, studies increase the years of overeducation, age (or experience) reduces it, and men have a more intense over-education than women. Family variables now show results that differ from the previous ones, as marriage is associated with fewer years of over-education, as are children.

According to model 1, and as with all other factors, upon arrival immigrants have an over-education that is 1.34 years more intense than that of Spaniards, which again suggests the incomplete portability of human capital acquired abroad. Knowledge acquired while living in Spain now also reduces over-education, specifically at a rate of 0.08 years of over-education for each year of residency, which means a notably slow pace of assimilation, as it would require 15 more years to completely eliminate the mismatch.

Models 2 and 3 show that, upon arrival in Spain, immigrants from Sub-Saharan Africa and Eastern Europe have almost two more years of over-education than Spaniards, and as such it is their origins which give their human capital lower portability. Immigrants from Asia and the Maghreb have, upon arrival, a year and a half more over-education than the native population, which reveals that their human capital also has limited transferability. The human capital of immigrants from Latin America and the Southern Cone has greater, but still limited, portability, whereas foreigners from developed economies bring human capital that is most suited to the job market, as shown by the fact that their over-education is, upon arrival, almost the same as that of Spaniards (a difference of only 0.3 years). It can thus be concluded once again that human capital from countries with a similar or higher level of development is almost completely equivalent to Spanish human capital, and human capital from the same cultural and language spheres is transferable to a very large degree. However, human capital acquired in countries with a lower level of economic and technological development, and with a distant culture and language, have a very imperfect portability. 
The multiplicative specifications of models 4 and 5 determine the degree of portability of studies and experience separately. Regarding studies, their limited transferability is confirmed, as each additional year of study in the country of origin means 0.3 years more of over-education for immigrants on the Spanish job market. Zero portability is also estimated for experience acquired by immigrants in their country of origin ${ }^{17}$.

The detail when observing areas of origin confirms much of the preceding conclusions. Thus, studies undertaken in Eastern Europe and Latin America, followed by those carried out in Africa and Asia, are limited in their transferability, as each additional year of study means 0.5 to 0.4 extra years of over-education. The most transferable studies are clearly those undertaken in the Southern Cone (0.2 more years of over-education), whereas, finally, studies undertaken in developed economies have complete portability. In the case of experience, three area types are observed. On the one hand, experience acquired in Sub-Saharan Africa and Eastern Europe does not bring any advantage on the Spanish job market. Surprisingly, the same occurs with experience acquired in developed countries, a fact that has no easy explanation, as it goes completely against the results for formal studies. On the other hand, experience acquired in the Southern Cone, the rest of Latin America and the Maghreb has high portability onto the Spanish job market. Finally, experience generated in Asia is not only non-transferable, it even has a negative effect, albeit minimally, as each year lived in Asia raises over-education by 0.02 years.

Models 4 and 5 also provide clear evidence of self-selection in migration. Specifically, immigrants arriving in Spain in recent years must have a wide range of unobservable positive characteristics which translate into their over-education being lower than that of Spaniards with similar observable characteristics. This self-selection is particularly important in the case of immigrants from Latin America, Asia and Eastern Europe. This however is lower among immigrants from the Southern Cone and does not occur at all among immigrants from developed countries. This result could be related to the differential costs of emigrating to Spain from different parts of the world, as self-

\footnotetext{
${ }^{17}$ Indeed, whereas for a Spaniard each year reduces their over-education by 0.01 years, for an immigrant the value of this coefficient is completely compensated by a similar contrary effect, so that the overall effect for immigrants is nil.
} 
selection is greatest among those with more geographically and culturally distant origins.

Finally, the various models show the pace of assimilation in over-education. As can be seen in models 1,2 and 4, the pace of assimilation ranges from 0.05 to 0.12 fewer years of over-education for each year of residency. In any case, this is a slow pace, as after ten years of living in Spain immigrants would only manage to reduce their over-education by 0.5 to 1.2 years. Models 3 and 5, which estimate the pace of assimilation by areas of origin, show that immigrants from Eastern Europe and Sub-Saharan Africa record the most intense pace of assimilation, though in the case of Africans the variable is only statistically significant at $10 \%$ in one of the models. Immigrants from developed economies assimilate more slowly, through their initial position is the least unfavourable. Now, also, Asian immigrants have no assimilation, so that their time in Spanish does not help to reduce their over-education and close the job and wage gap between them and the native population. Finally, the evidence on assimilation by immigrants from the rest of the areas is quite weak, as no assimilation is noted in one of the models, and in the other a slow assimilation is detected that is only statistically significant at $10 \%$. 
TABLE 7

Determinants of the intensity of over-education (number of years)

\begin{tabular}{|c|c|c|c|c|c|}
\hline Coefficients & Model 1 & Model 2 & Model 3 & Model 4 & Model 5 \\
\hline Male & $0.23 * * *$ & $0.22 * * *$ & $0.22 * * *$ & $0.22 * * *$ & $0.22 * * *$ \\
\hline Years of study & $0.25 * * *$ & $0.25 * * *$ & $0.25 * * *$ & $0.23 * * *$ & $0.23 * * *$ \\
\hline $\mathrm{x}$ Immigrant & & & & $0.29 * * *$ & \\
\hline x Developed economies & & & & & 0.03 \\
\hline x Eastern Europe & & & & & $0.48 * * *$ \\
\hline x Southern Cone & & & & & $0.21 * * *$ \\
\hline x Rest of Latin America & & & & & $0.50 * * *$ \\
\hline x Maghreb & & & & & $0.43 * * *$ \\
\hline x Rest of Africa & & & & & $0.41 * * *$ \\
\hline $\mathrm{x}$ Asia and rest of world & & & & & $0.40 * * *$ \\
\hline Age & $-0.01 * * *$ & $-0.01 * * *$ & $-0.01 * * *$ & $-0.01 * * *$ & $-0.01^{* * *}$ \\
\hline x Immigrant & & & & $0.01 * * *$ & \\
\hline x Developed economies & & & & & $0.01^{* *}$ \\
\hline x Eastern Europe & & & & & $0.01^{* *}$ \\
\hline x Southern Cone & & & & & 0.01 \\
\hline x Rest of Latin America & & & & & 0.00 \\
\hline x Maghreb & & & & & -0.02 \\
\hline x Rest of Africa & & & & & $0.01 * * *$ \\
\hline $\mathrm{x}$ Asia and rest of world & & & & & $0.03 * *$ \\
\hline Married & $-0.03^{* * *}$ & $-0.03^{*}$ & $-0.03 * *$ & $-0.03 * * *$ & $-0.03 * *$ \\
\hline Number of children & $-0.03 * * *$ & $-0.03 * * *$ & $-0.03 * * *$ & $-0.03 * * *$ & $-0.03 * * *$ \\
\hline Immigrant & $1.34 * * *$ & & & $-2.86 * * *$ & \\
\hline Developed economies & & $0.33^{* * *}$ & $0.33 * * *$ & & -0.45 \\
\hline Eastern Europe & & $1.66 * * *$ & $1.82 * * *$ & & $-4.79 * * *$ \\
\hline Southern Cone & & $0.98 * * *$ & $1.01 * * *$ & & $-2.13 * * *$ \\
\hline Rest of Latin America & & $1.40 * * *$ & $1.33^{* * *}$ & & $-4.86 * * *$ \\
\hline Maghreb & & $1.42 * * *$ & $1.47 * * *$ & & $-3.83 * * *$ \\
\hline Rest of Africa & & $1.53 * * *$ & $1.85 * * *$ & & $-4.44 * * *$ \\
\hline Asia and rest of world & & $1.24 * * *$ & $1.51 * * *$ & & $-4.82 * * *$ \\
\hline Years of residence & $-0.08 * * *$ & $-0.05 * * *$ & & $-0.12 * * *$ & \\
\hline x Developed economies & & & $-0.05^{*}$ & & $-0.06^{*}$ \\
\hline x Eastern Europe & & & $-0.12 * * *$ & & $-0.15 * * *$ \\
\hline x Southern Cone & & & $-0.06^{*}$ & & -0.08 \\
\hline x Rest of Latin America & & & $-0.02^{*}$ & & -0.12 \\
\hline x Maghreb & & & $-0.06^{*}$ & & -0.02 \\
\hline x Rest of Africa & & & $-0.14 *$ & & $-0.08 * * *$ \\
\hline $\mathrm{x}$ Asia and rest of world & & & -0.13 & & -0.05 \\
\hline Lambda & -0.07 & -0.13 & -0.13 & -0.07 & -0.13 \\
\hline $\mathrm{R}^{2}$ & 0.12 & 0.12 & 0.12 & 0.12 & 0.12 \\
\hline Observations & 124959 & 124959 & 124959 & 124959 & 124959 \\
\hline
\end{tabular}

Notes: The analysis was carried out using microdata from the 2001 Census by applying the mean criteria and by estimating linear regression models. All models include set provincial effects and a control variable for residents of towns with more than 20,000 inhabitants.

$*, * *$ and $* * *$ indicate that the coefficient is statistically significant at $10 \%, 5 \%$ and $1 \%$, respectively. 


\section{Conclusions}

This study analyses the portability of human capital of immigrants and their subsequent process of assimilation on the Spanish job market, having divided immigrants into seven regions of origin. Following recent works that combine both branches of the literature, the key variable for this study was over-education; however both incidence (an aspect usually considered in previous studies for other countries), and intensity were analysed.

Descriptive analysis shows that over-education affects immigrants more than the native population, but with important differences depending on their geographic origin, with a lower portability of human capital detected from countries with a lower level of development and with a distant language and culture. Immigrants also suffer a more intense over-education, particularly those from developing countries. The wage penalty that always accompanies over-education is also greater for immigrants in comparison with the Spanish population. For Africans, Asians and Eastern Europeans, the penalty is such that they receive no remuneration at all for their "surplus” years of study.

Econometric analysis, with discrete choice and regression models, shows that the portability of human capital is imperfect, given that as well as observable characteristics, immigrants have a more intense over-education than the native population, particularly those from Eastern Europe, Africa and Asia. The situation is comparatively better for immigrants from developed countries and the Southern Cone of South America, followed by the rest of Latin America. It can be confirmed, then, that human capital from countries with equal or greater economic and technological development is almost perfectly transferable to the Spanish job market, whereas human capital from countries with the same cultural and language background is reasonably portable. On the other hand, human capital acquired in geographic regions with lower development and with a distant culture and language have a very imperfect transferability.

It has also been shown that the low portability of human capital originates mainly in studies undertaken. Studies carried out in Sub-Saharan Africa, Eastern Europe, Asia and Latin America have a limited transferability, whereas studies undertaken in developed 
countries are totally transferable. The results regarding experience (age) are less robust: whereas the logit model provides favourable evidence for the full portability of experience acquired in origin, the linear regression model only provides results that are favourable for the portability of experience acquired in certain regions (Southern Cone, Latin America and the Maghreb). Experience acquired in Asia stands out not just for its zero portability but also for its counter-productive nature, to the extent that the greater the experience, the greater the over-education on the Spanish job market.

Similarly, abundant evidence is provided on self-selection in emigration, particularly in the case of origins that are more remote in both geographic and cultural terms. However, the evidence is less robust on self-selection in emigration from developed countries and Eastern Europe, indicating that, for these immigrants, emigration and subsequent adaptation in Spain could be less costly.

Finally, it can be confirmed that living in Spain it is possible to accumulate knowledge and experience that are perfectly adapted to the local job market, thus making for an easier assimilation process that reduces the intensity of over-education. The pace of assimilation however is notably slow, so that around fifteen years of living in Spain would be necessary to eliminate the educational mismatch. A quicker pace was detected for Eastern Europeans, and in the logit models for immigrants from the Maghreb. However, Asians and possibly Sub-Saharan Africans (as well as immigrants from the Southern Cone in some models) do not see their over-education reduced as their time in Spain increases. There is thus a high risk that immigrants from these regions remain permanently trapped in jobs with lower wages, regardless of their levels of education. 


\section{References}

Amuedo-Dorantes, C. and S. de la Rica (2007), "Labour Market Assimilation of Recent Immigrants in Spain”, British Journal of Industrial Relations, vol. 45, n. 2, pp. 257-284.

Baker, M. and D. Benjamin (1994), “The Performance of Immigrants in the Canadian Labor Market”, Journal of Labor Economics, vol. 12, n. 3, pp. 369-405.

Bell, B. (1997), “The Performance of Immigrants in the United Kingdom: Evidence from the GHS”, Economic Journal, vol. 107, n. 441, pp. 333-344.

Beneito, P., Ferri, J., Moltó, M.L. and E. Uriel (1996), Desajuste educativo y formación laboral especializada: efectos sobre los rendimientos salariales, IVIE, Working Paper EC 96-11.

Borjas, G. (1985), “Assimilation, Changes in Cohort Quality, and the Earnings of Immigrants”, Journal of Labor Economics, vol. 3, n. 4, pp. 463-489.

Borjas, G. (1995), “Assimilation and Changes in Cohort Quality Revisited: What Happened to Immigrant Earnings in the 1980s?”, Journal of Labor Economics, vol. 13, n. 21, pp. 201-245.

Chiswick, B. (1978), "The Effect of Americanization on the Earnings of Foreign-born Men”, Journal of Political Economy, vol. 86, n. 5, pp. 897-921.

Chiswick, B. and P. Miller (1995), “The endogeneity between language and earnings: an international analysis”, Journal of Labor Economics, vol. 13, n. 2, pp. 246288.

Chiswick, B. and P. Miller (2007), The International Transferability of Immigrants' Human Capital Skills, IZA Discussion paper n. 2670, March 2007, 27 p.

Chiswick, B. and P. Miller (2008), "Why is the payoff to schooling smaller for immigrants?”, Labour Economics, doi: 10.1016/j.labeco.2008.01.001.

Constant, A. and D. Massey (2003), "Self-selection, earnings, and out-migration: A longitudinal study of immigrants to Germany", Journal of Population Economics, vol. 16, pp. 631-653.

Duleep, H. and M. Regets (1997), "The Decline in Immigrant Entry Earnings: Less Transferable Skills or Lower Ability?”, The Quarterly Review of Economics and Finance, vol. 37, Special Issue, pp. 189-208.

Fernández, C. and C. Ortega (2008), "Labor market assimilation of immigrants in Spain: employment at the expense of bad job-matches?", Spanish Economic Review, vol. 10, n. 2, pp. 83-107. 
Friedberg, R. (2000), “You Can't Take It with You? Immigrant Assimilation and the Portability of Human Capital”, Journal of Labor Economics, vol. 18, n. 2, pp. 221-251.

Green, C.; P. Kler and G. Leeves (2007), "Immigrant overeducation: Evidence from recent arrivals to Australia”, Economics of Education Review 26, pp. 420-432.

Groot, W. and H. Maassen Van den Brink (2000), “Overeducation in the Labor Market: A Meta-Analysis”, Economics of Education Review vol. 19, pp. 149-158.

Kler, P. (2006), Overeducation among tertiary educated immigrants to Australia: A longitudinal study, Labour Economics Research Group, University of Queensland, Discussion Paper n. 9, January 2006, 39 p.

Lindley, J. and P. Lenton (2006), The Over-Education of UK Immigrants: Evidence from the Labour Force Survey, Sheffield Economic Research Paper Series n. 2006001, 20 p.

Longva, P. and O. Raaum (2003), "Earnings assimilation of immigrants in Norway - A reappraisal”, Journal of Population Economics, vol. 16, pp. 177-193.

Mendes de Oliveira, M., M. Santos and B. Kiker (2000), “The Role of Human Capital and Technological Change in Overeducation", Economics of Education Review, vol. 19, pp. 199-206.

Nielsen, Ch. P. (2007), Immigrant Overeducation: Evidence from Denmark, World Bank Policy Research Working Paper 4234, may 2007, 54 p.

OECD (2006), International Migration Outlook, Annual Report 2006, OECD, París.

OECD (2007), International Migration Outlook, Annual Report 2007, OECD, París.

Sanromá, E., R. Ramos and H. Simón (2005), Inmigración reciente en España: Sobreeducación y asimilación en el mercado de trabajo, mimeo.

Schmidt, C. (1992), Country of origin differences in the earnings of German immigrants, Discussion Paper 92-29, University of Munich.

Shields, M. and S. Wheatley Price (1998), "The earnings of male immigrants in England: evidence from the quarterly LFS”, Applied Economics, vol. 30, pp. 1157-1168.

Sicherman, N. (1991), “Overeducation in the Labour Market”, Journal of Labor Economics vol. 9, pp. 101-122.

Simón, H., R. Ramos and E. Sanromá (2007), Segregación laboral y estructuras salariales de nativos e inmigrantes en España. Un análisis con datos emparejados empresa-trabajador, IVIE, WP-EC 2007-03, 41 p. 
Simón, H., E. Sanromá and R. Ramos (2008), “Labour segregation and immigrant and native-born wage distributions in Spain: an analysis using matched employeremployee data”, Spanish Economic Review, vol. 10, n. 2, pp. 135-168. 